\title{
Association among cognitive function, physical fitness, and health status in older women
}

\author{
Suh-Jung Kang ${ }^{1, *}$, Byung-Hoon Kim² ${ }^{2}$ Hyo Lee', Jinsung Wang ${ }^{3}$ \\ 'Department of Sports and Health Care, College of Art and Culture, Sangmyung University, Seoul, Korea \\ ${ }^{2}$ Sports Science Research Center, Sangmyung University, Seoul, Korea \\ ${ }^{3}$ University of Wisconsin-Milwaukee, Milwaukee, WI, USA
}

This study examined the association among cognitive function, physical fitness, and health status in healthy older women. Ninety-four females aged from 62 to 86 years $(72.66 \pm 5.38$ years) from community healthcare centers and an exercise club in Seoul, South Korea. Cognitive function was assessed using the Seoul Neuropsychological Screening Battery. Physical performance comprised cardiorespiratory endurance, lower extremity strength, active balance ability, and walking speed. Health status included blood pressure and waist circumference. Multiple linear regression analyses were performed to determine the relationship among cognitive function, fitness components, and health status, with age and educational attainment as covariates. In the unadjusted model, attention was significantly associated with cardiovascular endurance $(B=0.19, P<0.05)$. Memory was significantly associated with lower limb strength $(B=0.77, P<0.05)$ and active balance ability $(B=2.35, P<0.05)$. In the adjusted model, attention was significantly associated with cardiovascular endurance $(B=0.15, P<0.05)$. Memory was significantly associated with lower limb strength $(B=0.87, P<0.05)$. In both models, cognitive function was not significantly associated with any health status variable. Though limited by a relatively small sample of female participants, who were healthy registrants of a community exercise program with normal cognitive function, the current study demonstrates that cognitive function is significantly associated with physical fitness, but not with health status, in healthy older women.

Keywords: Cognitive function, Cardiorespiratory endurance, Lower extremity strength, Active balance ability, Walking speed, Older women

\section{INTRODUCTION}

High levels of physical activity are associated with reduced risks of cognitive impairment, and physical activity has been emphasized as a protective factor against cognitive decline and dementia (Bangsbo et al., 2019; Laurin et al., 2001). Specifically, it has been shown that cardiorespiratory fitness is strongly associated with cognitive function in older women (Brown et al., 2010), and that higher cardiorespiratory fitness is beneficial in maintaining executive function in healthy older adults by enhancing the efficiency of the global brain network (Kawagoe et al., 2017). However, it has also been demonstrated that an exercise intervention can only improve aerobic fitness, and not cognitive function (Smiley-Oyen et al., 2008). Therefore, continued research on the association between cardiorespiratory fitness and cognitive function is needed.
Cardiovascular disease (CVD) risk factors are negatively correlated with mortality rate in older adults (Loprinzi et al., 2017). For example, waist circumference is known to be an established predictor of all-cause mortality (Adegbija et al., 2017), and also to be associated with cognitive function. Previous studies have reported that abdominal obesity based on waist circumference may be related to a higher probability of dementia (Chang et al., 2012). Furthermore, body mass index is thought to be associated with a reduced risk of cognitive decline in older adults after adjusting for waist circumference (Rodríguez-Fernández et al., 2017). In contrast, other studies have reported that cognitive function is not associated with waist circumference (Liu et al., 2019), and that a larger waist circumference is associated with better attention memory (Takashi et al., 2020).

Walking capacity is a useful health index that reflects physical
${ }^{*}$ Corresponding author: Suh-Jung Kang (iD https://orcid.org/0000-0002-8284-9299 Department of Sports and Health Care, College of Art and Culture, Sangmyung University, 20 Hongjimun 2-gil, Jongno-gu, Seoul 03016, Korea Email: suhjkang@smu.ac.kr

Received: December 29, 2021 / Accepted: January 16, 2022
This is an Open Access article distributed under the terms of the Creative Commons Attribution Non-Commercial License (https://creativecommons.org/licenses/by-nc/4.0/) which permits unrestricted non-commercial use, distribution, and reproduction in any medium, provided the original work is properly cited. 
performance ability, which determines quality of life. Walking impairment is an indicator of aging, and is primarily linked to the development of dementia (Beauchet et al., 2016). For instance, people with cognitive impairment display a lower walking speed (Tian et al., 2017), which is a predictor of cognitive decline and dementia (Gale et al., 2014; Quan et al., 2017). However, some studies have reported discrepant findings, which indicated that walking speed was only partially correlated with cognitive function (Atkinson et al., 2010; Callisaya et al., 2015).

Lower extremity muscular strength and balance ability both can affect walking capacity and are key neuromuscular components for identifying older adults at risk (Muehlbauer et al., 2015), and thus, improvement in the two components should be the target of interventions for fall prevention (Clemson et al., 2012). Improvement in cognitive function is also important for fall prevention, given that cognitive impairment is a fall risk factor (Muir et al., 2012). Furthermore, dementia elevates fall risk (Horikawa et al., 2005), which can increase by up to $20 \%$ with each one-point decline in the Mini-Mental State Examination (MMSE) score (Gleason et al., 2009). These findings suggest that fall-related fitness, falls, and cognitive function are mutually associated.

The aforementioned findings indicate a potentially meaningful association between cognitive function and a number of factors (e.g., cardiorespiratory fitness, waist circumference, walking ability, lower extremity muscular strength) in older adults; and yet, the association between them are inconclusive due to the discrepant findings. In addition, the association has been studied between cognition and physical fitness and also between cognition and health status, but only in separate studies. In this study, thus, we aimed to investigate in a single study the association among cognitive function, physical fitness (cardiorespiratory endurance, lower extremity muscular strength, active balance ability, walking speed), and health status (blood pressure, waist circumference) systematically in healthy older women.

\section{MATERIALS AND METHODS}

\section{Participants}

Potential participants of exercise classes were recruited from four community healthcare centers and one private education center for senior in Seoul, South Korea from 2017 to 2019. The inclusion criteria were: (1) neurologically intact women aged 62 years and older, and (2) normal cognitive function, as assessed via the Korean MMSE ( $\geq 24$ ) (Kukull et al., 1994). To ensure that the participants could perform the tasks employed in the current study, and also to minimize potential risks, the following exclusion criteria were used: a history of severe CVD, neurological disease, peripheral disorder, significant orthopedic conditions, or visual impairment. Final data from a total of 94 women aged from 62 to 86 years (72.66 \pm 5.38 years) were used in statistical analyses; and four samples with missing values were excluded from the analysis (listwise deletion).

All participants participated in the study voluntarily, and informed consent was obtained from them prior to their inclusion in the study. This study was approved by Institutional Review Board of the Sangmyung University (\# BE2017-26).

\section{Measurements}

Cognitive function was assessed using the Seoul Neuropsychological Screening Battery (SNSB-II) (Kim et al., 2021) by certified clinical psychologists. Scores for attention, visuospatial function, memory, and frontal/executive function were calculated, and the T-score of each variable was used for analysis.

To determine the participant's physical fitness level, we included the following measures: cardiorespiratory endurance, lower extremity muscle strength, active balance ability, and walking speed. Cardiorespiratory endurance was measured by the number of times the participant could walk in place for $2 \mathrm{~min}$, with the knee lifted to $70^{\circ}$. Lower extremity muscle strength was measured by the number of sit-to-stand repetitions for $30 \mathrm{sec}$. Active balance ability was measured as the time taken to stand up from a chair, reach a target $3 \mathrm{~m}$ ahead and return to the chair as quickly as possible. All measurements were performed in accordance with the guidelines for older adults. Walking speed was measured based on the time taken to walk $8 \mathrm{~m}$ at one's usual pace (Hackett et al., 2018; Jerome et al., 2015). However, we extended the distance by $2 \mathrm{~m}$ at the start and finish, creating a total of $12 \mathrm{~m}$. This was done because walking speed may decrease at the start and finish. Walking speed was calculated as distance/time $(\mathrm{m} / \mathrm{sec})$.

To determine the participant's general health status, we included the following measures: blood pressure and waist circumference. Blood pressure was measured twice using a mercury sphygmomanometer, and the average of the two measurements was used in the analysis. Waist circumference was measured using a tape measure around the umbilicus on bare skin after the participant exhaled and did not hold their breath. The tape measure was placed flat and parallel to the skin, without applying excessive pressure.

\section{Data analysis}

Multiple linear regression analyses were performed to estimate 
Table 1. Characteristics of the participants

\begin{tabular}{lc}
\hline Characteristic & Value \\
\hline Age (yr) & $72.66 \pm 5.38$ \\
Education & \\
Elementary or less & $28(29.79)$ \\
Middle school & $23(24.27)$ \\
High school & $19(20.21)$ \\
College or more & $24(25.53)$ \\
Cognitive function & \\
Attention & $51.80 \pm 11.11$ \\
Visuospatial & $50.13 \pm 14.66$ \\
Memory & $52.16 \pm 9.08$ \\
Frontal/executive function & $55.07 \pm 13.50$ \\
Physical fitness & \\
Cardiorespiratory endurance (reps) & $108.39 \pm 15.95$ \\
Lower extremity muscle strength (reps) & $16.45 \pm 3.61$ \\
Active balance ability (sec) & $7.52 \pm 1.13$ \\
Walking speed (m/sec) & $0.64 \pm 0.12$ \\
Health status & \\
Waist circumference (cm) & $85.80 \pm 11.09$ \\
Systolic blood pressure (mmHg) & $134.38 \pm 16.10$ \\
Diastolic blood pressure (mmHg) & $77.0 \pm 11.09$ \\
Normal blood pressure & $21(22.35)$ \\
Prehypertension & $38(40.42)$ \\
Hypertension & $35(37.23)$ \\
\hline
\end{tabular}

Values are presented as mean \pm standard deviation or number (\%).

the association among the aforementioned variables related to cognitive function, physical fitness, and health status (Table 1). Sociodemographic measures included age and educational attainment (calculated as years of education), which were controlled as covariates (Best et al., 2016; Dumurgier et al., 2017). Educational attainment was included because it has been suggested to influence cognitive function in older adults (Stern et al., 1994; Wilson et al., 2009; Yaffe et al., 2009).

\section{RESULTS}

Table 1 shows the means of all study parameters. To analyze the relationship among cognitive function, physical fitness, and health status, we performed analyses with and without adjusting for age and educational attainment (Tables 2, 3). According to the unadjusted model, attention was significantly associated with cardiovascular endurance $(\mathrm{B}=0.19, P<0.05)$. Memory was significantly associated with lower limb strength $(\mathrm{B}=0.77, P<0.05)$ and active balance ability $(\mathrm{B}=2.35, P<0.05)$. Visuospatial and executive functions were not significantly associated with any of the tested

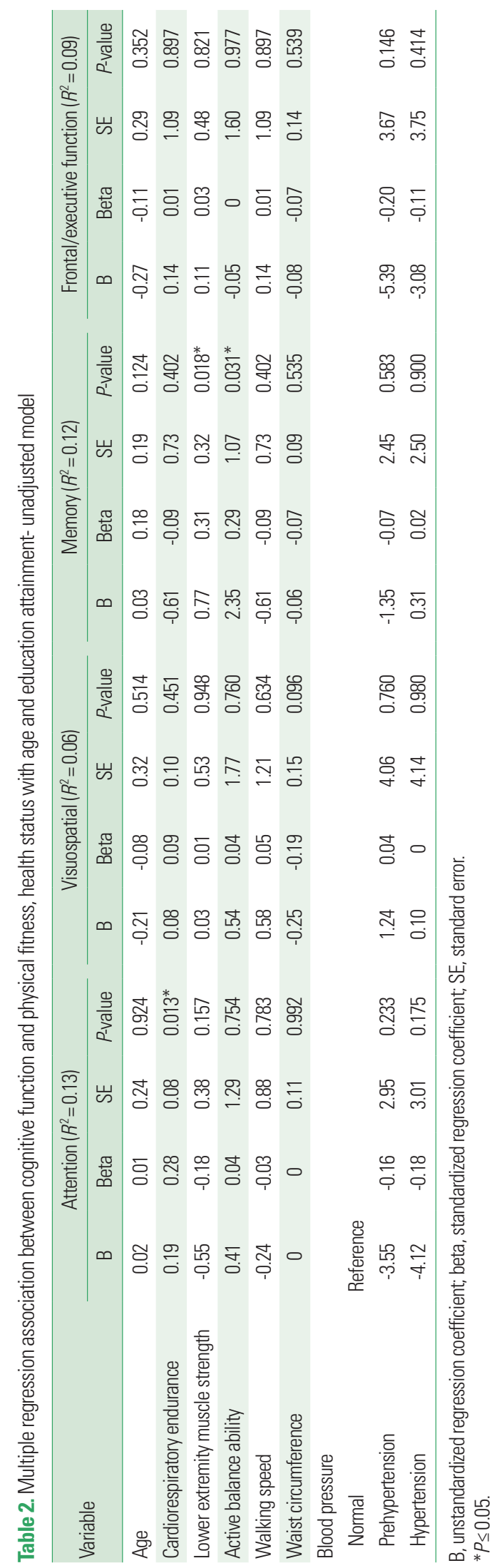




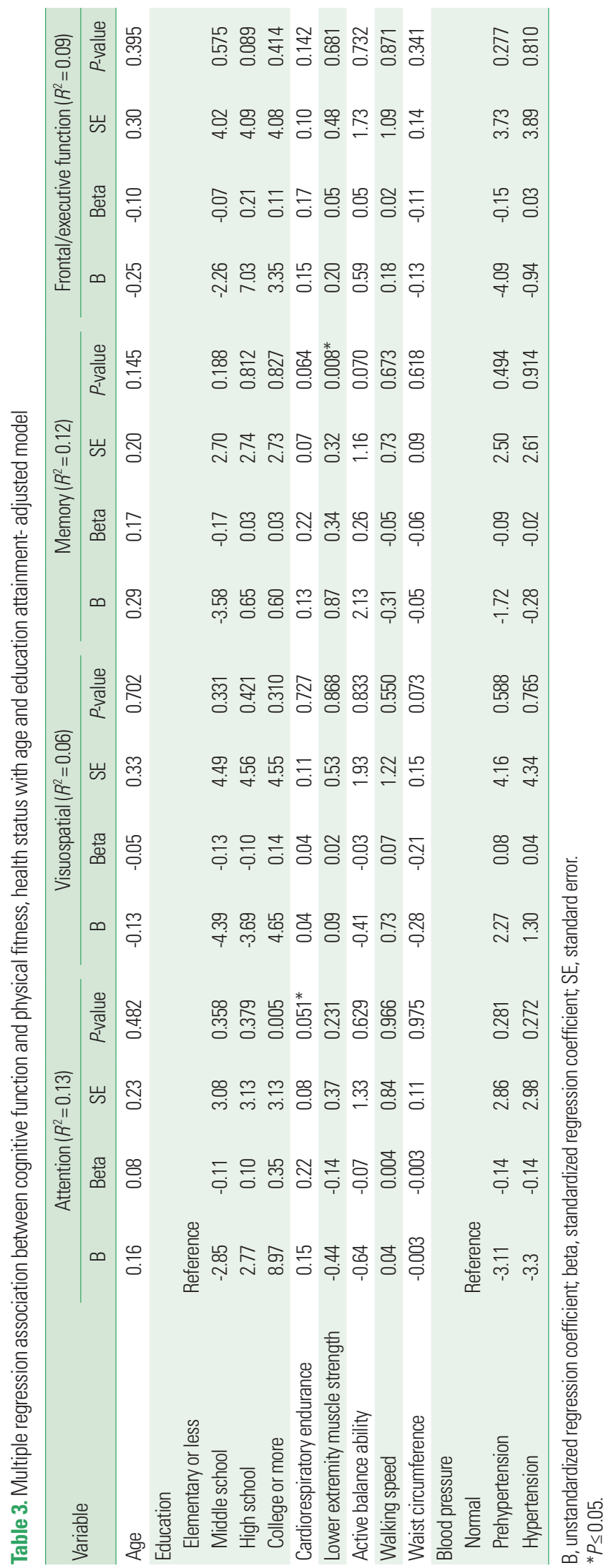

variables. Similar results were observed for the adjusted model. Attention was significantly associated with cardiovascular endurance $(\mathrm{B}=0.15, P<0.05)$. Memory was significantly associated with lower limb strength $(\mathrm{B}=0.87, P<0.05)$. Visuospatial and frontal/executive functions were not significantly associated with any of the tested variables.

\section{DISCUSSION}

This study aimed to investigate the relationship among cognitive function, physical fitness, and health status in healthy older women. We found that cognitive function was significantly associated with certain physical fitness parameters, but not with walking speed and any health status parameters.

Among the various factors of physical fitness, cardiorespiratory fitness is an independent predictor of cognitive function that is associated with all-cause mortality (Brown et al., 2010; Kawagoe et al., 2017). In addition, lower extremity strength and active balance ability deteriorate with aging and are associated with fall risk (Clemson et al., 2012; Muehlbauer et al., 2015). Falls among older adults cause secondary health problems, deteriorate physical fitness, and induce cognitive decline and depression (Muir et al., 2012). Thus, both lower extremity muscle strength and balance ability are important factors that are strongly associated with both physical and brain health in older adults. Although we had a relatively small sample of 94 participants in contrast to past cross-sectional studies with larger study populations, we still observed a significant correlation between cognitive function and physical fitness, regardless of the covariates (age, education). Hence, our results strongly support and emphasize the positive relationship between physical fitness and cognitive function.

Because of the nature of the cross-sectional design, we could not establish a causality between cognitive decline and deteriorated physical fitness. A previous longitudinal study reported that cognitive function decrements precede or co-occur with physical performance decline (Atkinson et al., 2010). Furthermore, a study examining the relationship among CVD risk factors, cognitive function, and mortality risk showed that individuals with poor cognitive function had a high mortality risk, irrespective of their CVD risk factors (Loprinzi et al., 2017). However, CVD risk factors are still associated with cognitive function, and this relationship is also influenced by physical fitness, which is a predictor of and mutually associated with cognitive function (Daimiel et al., 2020). Moreover, physical fitness mediates the effect of aging on cognitive function, suggesting physical activity as a major factor 
in preventing cognitive decline in older adults (Pérez-Sousa et al., 2021). Therefore, our results support previous findings and highlight the importance of physical fitness reducing or slowing cognitive decline with aging.

Walking is typically perceived as an automated motor task, although it is a complex task that involves higher levels of cognitive function (Hausdorff et al., 2005) as it requires integration of attention, planning, memory, motor, perceptual, and cognitive processes (Mulder et al., 2002). Previous studies have reported that slow walking speed is associated with cognitive decline (Rosano et al., 2005), which in turn is associated with the preclinical stage of dementia (Marquis et al., 2002; Verghese et al., 2002). Moreover, the risk of dementia is higher among those with slow walking speed or severe reductions in walking speed over time (Hackett et al., 2018). These results suggest that preventing the reduction of walking speed with aging may have health benefits. Interestingly, however, our results showed that none of the cognitive functions was significantly associated with walking speed. It has been shown that the association between walking speed and cognitive function varies depending on how walking speed is measured (e.g., walking at one's normal pace or as fast as possible) (Clouston et al., 2013): when walking at a normal pace, walking speed was not associated with one's mental state; when walking as fast as possible, however, it was (Deshpande et al., 2009). Similarly, fast walking has been shown to be associated with cognitive decline more than normal walking or walking while talking (Deshpande et al., 2009). The reason may be that compared to normal walking, fast walking is related more to the individual's physical fitness, such as lower extremity muscular strength, balance, and functional capacity. These findings may explain the lack of a statistically significant association between cognitive function and walking speed in the present study, given that we measured walking speed at a normal pace. A more thorough investigation of the relationship between varying walking speeds (especially fast walking) and cognitive function is warranted in future studies.

Moreover, the lack of a statistically significant association between cognitive function and walking speed in our study may also be attributable to the small sample size, compared to previous large population-based studies with a study population of greater than 1,000 . However, a study conducted among 2,938 participants without dementia or severe walking impairment reported that low baseline walking speed was associated with the onset of dementia within 6 years although baseline walking speed and dementia were not correlated (Welmer et al., 2014). This shows that walking speed may play an important role in processing speed of dementia over time. Therefore, although our cross-sectional study did not find a significant association between walking speed and cognitive function, we believe the findings have valuable implications for the management of cognitive decline or dementia risk in the long term.

Previous findings suggest that blood pressure and waist circumference are CVD risk factors and are linked to cognitive function (Kanaya et al., 2009; Tadic et al., 2016), based on which we hypothesized that high blood pressure and a large waist circumference would be significantly associated with poor cognitive function. Liu et al. (2019) found that waist circumference was independently and significantly associated with cognitive impairment in adults aged 70 years or older. Moreover, participants with an abnormally large waist circumference were at 1.8 times greater risk for poor cognitive function. In addition, a large-scale cohort study involving 872,082 adults aged 65 years or older reported that abdominal obesity, as measured by waist circumference, significantly increased the risk of dementia (Cho et al., 2019). However, contradictory findings have also been reported, showing an association between lower abdominal fat mass and worse cognitive function in elderly women (Bagger et al., 2004). In addition, a larger waist circumference was associated with better cognitive function among women and men aged between 65 and 74 years (Takashi et al., 2020). These findings collectively suggest that the impact of increased abdominal fat on cognitive function may vary with age and sex (Takashi et al., 2020). The mean waist circumference of our participants was $85.8 \pm 11.09 \mathrm{~cm}$, which is slightly above the World Health Organization criteria for obesity in the Korean population. Our current findings indicate that waist circumference is not significantly associated with cognitive function at least in Korean older women (aged over 62 years) who are slightly obese.

Regarding blood pressure, the prevalence of hypertension is $50.7 \%$ among Korean women in their 60 s and $72.4 \%$ among those aged 70 years or older (Korea Centers for Disease Control and Prevention, 2020). Our study population comprised people with relatively healthy waist circumference and blood pressure according to age- and sex-specific criteria, and the composition of the study population may have influenced the study outcomes. The lack of a significant relationship between blood pressure and cognitive function in our current study may be attributable to the fact that the majority of the participants in this study had normal blood pressure or were at the stage of prehypertension (Table 1). Previous findings indicate that reduced brain circulation caused by aging decreases resting cerebral blood flow and causes functional impairment, thus causing hypertension-related cognitive 
dysfunction (Gąsecki et al., 2013). Moreover, arterial stiffness, rather than blood pressure, is a stronger predictor of cognitive function (Hajjar et al., 2016). Thus, it would have been difficult to observe a statistically significant result regarding blood pressure in this study, especially given that fewer than half of our participants had high blood pressure. Additionally, interactions among other factors, which include health behavior, health conditions, use of medication, motor ability, reduced physical fitness, and body composition changes, may have influenced the relationship between blood pressure and cognitive function (Altschul et al., 2020). Thus, subsequent studies may want to consider recruiting a larger sample consisting of participants with a wider range of blood pressure and investigating the relationship between different ranges of blood pressure and cognitive function separately.

It is worth noting that a significant correlation was observed between cognitive function and physical fitness parameters, regardless of educational attainment, which has been suggested to influence cognitive function in older adults. Stern et al. (1994) conducted a cross-sectional study in which 593 older adults were examined for 4 years, and reported that the risk of dementia was increased in subjects with low education. Yaffe et al. (2009) also argued that educational attainment needs to be taken into consideration when interpreting data regarding cognitive function in older adults. However, Wilson et al. (2009) reported, based on the data from more than 6,000 older adults who were interviewed for up to 14 years, that education is associated with level of cognitive function, but not with rate of cognitive decline. Our current findings add to the literature, by suggesting that the level of educational attainment does not play a big role in determining the association among cognition, physical fitness, and health status in Korean older women.

One strength of the present study is that we performed concurrent assessments of physical fitness, walking speed, health status, and cognitive function. In addition, we used a validated cognitive function instrument (SNSB-II) (Kim et al., 2021) instead of a simple questionnaire to assess cognitive function (Best et al., 2016; Laurin et al., 2001). This study also has several limitations. First, the sample size was relatively small, compared to some previous studies in which the number of participants exceeded 1,000 (Makizako et al., 2015; Mielke et al., 2013); and the sample included the registrants of a community exercise program who had normal cognitive function and were deemed sufficiently physically healthy to participate in an exercise program. In addition, we limited our sample to female participants (women in clinical trials are likely to be healthier than the general population, which limits confound- ers) (Atkinson et al., 2010). In relation to addressing these limitations, future studies should consider testing a larger sample consisting of both male and female participants to determine the association between cognitive function and physical fitness, especially by investigating the effects of additional factors that may have influence in cognitive function, such as one's physical activity level (e.g., active vs. sedentary), sedentary time, and alcohol consumption. Employing a quantitative gait analysis in such investigations would also be beneficial.

In conclusion, certain aspects of cognitive function (attention, memory) were significantly correlated with some of the physical fitness parameters (cardiovascular endurance, lower limb strength, active balance ability) measured in the current study; however, none of the cognitive functions was significantly correlated with walking speed and health status (blood pressure, waist circumference) in our participants who were healthy Korean women aged from 62 to 86 years. Our findings suggest the importance of maintaining or improving physical fitness to avoid cognitive function decline associated with aging.

\section{CONFLICT OF INTEREST}

No potential conflict of interest relevant to this article was reported.

\section{ACKNOWLEDGMENTS}

This work was supported by the National Research Foundation of Korea Grant funded by the Korean Government (NRF-2017 S1A20322920).

\section{REFERENCES}

Adegbija O, Hoy WE, Dong B, Wang Z. Body mass index and waist circumference as predictors of all-cause mortality in an Aboriginal Australian community. Obes Res Clin Pract 2017;11:19-26.

Altschul D, Starr J, Deary I. Blood pressure and cognitive function across the eighth decade: a prospective study of the Lothian Birth Cohort of 1936. BMJ Open 2020;10:e033990.

Atkinson HH, Rapp SR, Williamson JD, Lovato J, Absher JR, Gass M, Henderson VW, Johnson KC, Kostis JB, Sink KM, Mouton CP, Ockene JK, Stefanick ML, Lane DS, Espeland MA. The relationship between cognitive function and physical performance in older women: results from the women's health initiative memory study. J Gerontol A Biol Sci Med Sci 2010;65:300-306. 
Bagger YZ, Tankó LB, Alexandersen P, Qin G, Christiansen C. The implications of body fat mass and fat distribution for cognitive function in elderly women. Obes Res 2004;12:1519-1526.

Bangsbo J, Blackwell J, Boraxbekk CJ, Caserotti P, Dela F, Evans AB, Jespersen AP, Gliemann L, Kramer AF, Lundbye-Jensen J, Mortensen EL, Lassen AJ, Gow AJ, Harridge SDR, Hellsten Y, Kjaer M, Kujala UM, Rhodes RE, Pike ECJ, Skinner T, Skovgaard T, Troelsen J, Tulle E, Tully MA, van Uffelen JGZ, Viña J. Copenhagen consensus statement 2019: physical activity and ageing. Br J Sports Med 2019;53:856-858.

Beauchet O, Annweiler C, Callisaya ML, De Cock AM, Helbostad JL, Kressig RW, Srikanth V, Steinmetz JP, Blumen HM, Verghese J, Allali G. Poor gait performance and prediction of dementia: results from a meta-analysis. J Am Med Dir Assoc 2016;17:482-490.

Best JR, Liu-Ambrose T, Boudreau RM, Ayonayon HN, Satterfield S, Simonsick EM, Studenski S, Yaffe K, Newman AB, Rosano C; Health, Aging and Body Composition Study. An evaluation of the longitudinal, bidirectional associations between gait speed and cognition in older women and men. J Gerontol A Biol Sci Med Sci 2016;71:16161623.

Brown AD, McMorris CA, Longman RS, Leigh R, Hill MD, Friedenreich CM, Poulin MJ. Effects of cardiorespiratory fitness and cerebral blood flow on cognitive outcomes in older women. Neurobiol Aging 2010; 31:2047-2057.

Callisaya ML, Blizzard CL, Wood AG, Thrift AG, Wardill T, Srikanth VK. Longitudinal relationships between cognitive decline and gait slowing: the Tasmanian Study of Cognition and Gait. J Gerontol A Biol Sci Med Sci 2015;70:1226-1232.

Chang WS, Won KH, Lee JY, Kim ET, Kweon HJ. The relationship between obesity and the high probability of dementia based on the body mass index and waist circumference. Korean J Fam Med 2012;33:17-24.

Cho GJ, Hwang SY, Lee KM, Choi KM, Hyun Baik S, Kim T, Han SW, Yoo HJ. Association between waist circumference and dementia in older persons: A nationwide population-based study. Obesity 2019;27:18831891.

Clemson L, Fiatarone Singh MA, Bundy A, Cumming RG, Manollaras K, O'Loughlin P, Black D. Integration of balance and strength training into daily life activity to reduce rate of falls in older people (the LiFE study): randomised parallel trial. BMJ 2012;345:e4547.

Clouston SA, Brewster P, Kuh D, Richards M, Cooper R, Hardy R, Rubin MS, Hofer SM. The dynamic relationship between physical function and cognition in longitudinal aging cohorts. Epidemiol Rev 2013;35: 33-50.

Daimiel L, Martínez-González MA, Corella D, Salas-Salvadó J, Schröder H, Vioque J, Romaguera D, Martínez JA, Wärnberg J, Lopez-Miranda J, Estruch R, Cano-Ibáñez N, Alonso-Gómez A, Tur JA, Tinahones FJ,
Serra-Majem L, Micó-Pérez RM, Lapetra J, Galdón A, Pintó X, Vidal J, Micó V, Colmenarejo G, Gaforio JJ, Matía P, Ros E, Buil-Cosiales P, Vázquez-Ruiz Z, Sorlí JV, Graniel IP, Cuenca-Royo A, Gisbert-Sellés C, Galmes-Panades AM, Zulet MA, García-Ríos A, Díaz-López A, de la Torre R, Galilea-Zabalza I, Ordovás JM. Physical fitness and physical activity association with cognitive function and quality of life: baseline cross-sectional analysis of the PREDIMED-Plus trial. Sci Rep 2020;10: 3472.

Deshpande N, Metter EJ, Bandinelli S, Guralnik J, Ferrucci L. Gait speed under varied challenges and cognitive decline in older persons: a prospective study. Age Ageing 2009;38:509-514.

Dumurgier J, Artaud F, Touraine C, Rouaud O, Tavernier B, Dufouil C, Singh-Manoux A, Tzourio C, Elbaz A. Gait speed and decline in gait speed as predictors of incident dementia. J Gerontol A Biol Sci Med Sci 2017;72:655-661.

Gale CR, Allerhand M, Sayer AA, Cooper C, Deary IJ. The dynamic relationship between cognitive function and walking speed: the English Longitudinal Study of Ageing. Age (Dordr) 2014;36:9682.

Gąsecki D, Kwarciany M, Nyka W, Narkiewicz K. Hypertension, brain damage and cognitive decline. Curr Hypertens Rep 2013;15:547-558.

Gleason CE, Gangnon RE, Fischer BL, Mahoney JE. Increased risk for falling associated with subtle cognitive impairment: secondary analysis of a randomized clinical trial. Dement Geriatr Cogn Disord 2009;27: 557-563.

Hackett RA, Davies-Kershaw H, Cadar D, Orrell M, Steptoe A. Walking speed, cognitive function, and dementia risk in the english longitudinal study of ageing. J Am Geriatr Soc 2018;66:1670-1675.

Hajjar I, Goldstein FC, Martin GS, Quyyumi AA. Roles of arterial stiffness and blood pressure in hypertension-associated cognitive decline in healthy adults. Hypertension 2016;67:171-175.

Hausdorff JM, Yogev G, Springer S, Simon ES, Giladi N. Walking is more like catching than tapping: gait in the elderly as a complex cognitive task. Exp Brain Res 2005;164:541-548.

Horikawa E, Matsui T, Arai H, Seki T, Iwasaki K, Saaki H. Risk of falls in Alzheimer's disease: a prospective study. Intern Med 2005;44:717-721.

Jerome GJ, Ko SU, Kauffman D, Studenski SA, Ferrucci L, Simonsick EM. Gait characteristics associated with walking speed decline in older adults: results from the Baltimore Longitudinal Study of Aging. Arch Gerontol Geriatr 2015;60:239-243.

Kanaya AM, Lindquist K, Harris TB, Launer L, Rosano C, Satterfield S, Yaffe K; Health ABC Study. Total and regional adiposity and cognitive change in older adults: The Health, Aging and Body Composition (ABC) study. Arch Neurol 2009;66:329-335.

Kawagoe T, Onoda K, Yamaguchi S. Associations among executive function, cardiorespiratory fitness, and brain network properties in older 
adults. Sci Rep 2017;7:40107.

Kim H, Yu KH, Lee BC, Kim BC, Kang Y. Validity of the Montreal Cognitive Assessment (MoCA) index scores: a comparison with the cognitive domain scores of the Seoul Neuropsychological Screening Battery (SNSB). Dement Neurocogn Disord 2021;20:28-37.

Korea Centers for Disease Control and Prevention. 8th Korea National Health and Nutrition Examination Survey 2020 [Internet]. Cheongju (Korea): Korea Centers for Disease Control and Prevention; 2020 [cited 2021 Dec 28]. Available from: https://knhanes.kdca.go.kr/knhanes/ main.do.

Kukull WA, Larson EB, Teri L, Bowen J, McCormick W, Pfanschmidt ML. The Mini-Mental State Examination score and the clinical diagnosis of dementia. J Clin Epidemiol 1994;47:1061-1067.

Laurin D, Verreault R, Lindsay J, MacPherson K, Rockwood K. Physical activity and risk of cognitive impairment and dementia in elderly persons. Arch Neurol 2001;58:498-504.

Liu Z, Yang H, Chen S, Cai J, Huang Z. The association between body mass index, waist circumference, waist-hip ratio and cognitive disorder in older adults. J Public Health (Oxf) 2019;41:305-312.

Loprinzi PD, Crush E, Joyner C. Cardiovascular disease biomarkers on cognitive function in older adults: joint effects of cardiovascular disease biomarkers and cognitive function on mortality risk. Prev Med 2017;94:27-30.

Makizako H, Shimada H, Doi T, Tsutsumimoto K, Lee S, Hotta R, Nakakubo S, Harada K, Lee S, Bae S, Harada K, Suzuki T. Cognitive functioning and walking speed in older adults as predictors of limitations in self-reported instrumental activity of daily living: prospective findings from the Obu Study of Health Promotion for the Elderly. Int J Environ Res Public Health 2015;12:3002-3013.

Marquis S, Moore MM, Howieson DB, Sexton G, Payami H, Kaye JA, Camicioli R. Independent predictors of cognitive decline in healthy elderly persons. Arch Neurol 2002;59:601-606.

Mielke MM, Roberts RO, Savica R, Cha R, Drubach DI, Christianson T, Pankratz VS, Geda YE, Machulda MM, Ivnik RJ, Knopman DS, Boeve BF, Rocca WA, Petersen RC. Assessing the temporal relationship between cognition and gait: slow gait predicts cognitive decline in the Mayo Clinic Study of Aging. J Gerontol A Biol Sci Med Sci 2013;68: 929-937.

Muehlbauer T, Gollhofer A, Granacher U. Associations between measures of balance and lower-extremity muscle strength/power in healthy individuals across the lifespan: a systematic review and meta-analysis. Sports Med 2015;45:1671-1692.

Muir SW, Gopaul K, Montero Odasso MM. The role of cognitive impairment in fall risk among older adults: a systematic review and metaanalysis. Age Ageing 2012;41:299-308.
Mulder T, Zijlstra W, Geurts A. Assessment of motor recovery and decline. Gait Posture 2002;16:198-210.

Pérez-Sousa MÁ, Del Pozo-Cruz J, Olivares PR, Cano-Gutiérrez CA, Izquierdo M, Ramírez-Vélez R. Role for physical fitness in the association between age and cognitive function in older adults: a mediation analysis of the SABE Colombia Study. Int J Environ Res Public Health 2021;18:751.

Quan M, Xun P, Chen C, Wen J, Wang Y, Wang R, Chen P, He K. Walking pace and the risk of cognitive decline and dementia in elderly populations: a meta-analysis of prospective cohort studies. J Gerontol A Biol Sci Med Sci 2017;72:266-270.

Rodríguez-Fernández JM, Danies E, Martínez-Ortega J, Chen WC. Cognitive decline, body mass index, and waist circumference in communitydwelling elderly participants. J Geriatr Psychiatry Neurol 2017;30: 67-76.

Rosano C, Simonsick EM, Harris TB, Kritchevsky SB, Brach J, Visser M, Yaffe K, Newman AB. Association between physical and cognitive function in healthy elderly: the health, aging and body composition study. Neuroepidemiology 2005;24:8-14.

Smiley-Oyen AL, Lowry KA, Francois SJ, Kohut ML, Ekkekakis P. Exercise, fitness, and neurocognitive function in older adults: the "selective improvement" and "cardiovascular fitness" hypotheses. Ann Behav Med 2008;36:280-291.

Stern Y, Gurland B, Tatemichi TK, Tang MX, Wilder D, Mayeux R. Influence of education and occupation on the incidence of Alzheimer's disease. JAMA 1994;271:1004-1010.

Tadic M, Cuspidi C, Hering D. Hypertension and cognitive dysfunction in elderly: blood pressure management for this global burden. BMC Cardiovasc Disor 2016;16:208.

Takashi W, Tanaka-Mizuno S, Takashima N, Takechi H, Hayakawa T, Miura K, Ueshima H, Kita Y, Dodge HH. Waist circumference and domain-specific cognitive function among non-demented Japanese older adults stratified by sex: results from the Takashima Cognition Study. J Alzheimers Dis 2020;73:887-896.

Tian Q, An Y, Resnick SM, Studenski S. The relative temporal sequence of decline in mobility and cognition among initially unimpaired older adults: results from the Baltimore Longitudinal Study of Aging. Age Ageing 2017;46:445-451.

Verghese J, Lipton RB, Hall CB, Kuslansky G, Katz MJ, Buschke H. Abnormality of gait as a predictor of non-Alzheimer's dementia. N Engl J Med 2002;347:1761-1768.

Welmer AK, Rizzuto D, Qiu C, Caracciolo B, Laukka EJ. Walking speed, processing speed, and dementia: a population-based longitudinal study. J Gerontol A Biol Sci Med Sci 2014;69:1503-1510.

Wilson RS, Hebert LE, Scherr PA, Barnes LL, Mendes de Leon CF, Evans 
DA. Educational attainment and cognitive decline in old age. Neurology 2009;72:460-465.

Yaffe K, Fiocco AJ, Lindquist K, Vittinghoff E, Simonsick EM, Newman
AB, Satterfield S, Rosano C, Rubin SM, Ayonayon HN, Harris TB; Health ABC Study. Predictors of maintaining cognitive function in older adults: the Health ABC study. Neurology 2009;72:2029-2035. 